\title{
Cat-scratch disease presenting as the oculoglandular syndrome of Parinaud: a report of two cases
}

\author{
A.S.M. Jawad ${ }^{1}$ and A.A.A. Amen ${ }^{2}$ \\ ${ }^{1}$ Chase Farm Hospital, The Ridgeway, Enfield, Middlesex EN2 8JL and ${ }^{2}$ St Margaret's Hospital, Epping, \\ Essex CM16 6 TN, UK.
}

\begin{abstract}
Summary: We report the case histories of a 50 year old man and 14 year old daughter who presented with the oculoglandular syndrome of Parinaud caused by cat-scratch disease.
\end{abstract}

\section{Introduction}

Cat scratch disease (CSD) is usually a mild selflimiting illness characterized by regional lymphadenitis occurring 2 to 3 weeks after an injury to the skin by a scratch from a cat. Recent evidence describes small, pleomorphic Gram-negative bacteria as the causative organisms..$^{1-4}$ The main proponents of this hypothesis attempted to fulfil Koch's postulates in an animal model (armadillo), though only skin lesions and not the full picture of CSD resulted.

We report the case histories of a 50 year old man and his 14 year old daughter who presented with the oculoglandular syndrome of Parinaud caused by CSD.

\section{Case reports}

A 50 year old man presented with a 2-week history of swelling of the lower and to a lesser extent the upper eyelids of the left eye, and a 5 day history of a swelling in the left parotid region. Both swellings gradually increased in size and were associated with some discomfort. The patient felt systemically unwell but had no temperature.

Physical examination revealed chemosis and swelling of the lower and less so the upper eyelids of the left eye with congestion of the palpebral conjunctiva. There was also $4 \times 4 \mathrm{~cm}$ swelling present just anterior to the left tragus. The swelling was firm and attached to the skin. There was local tenderness with some overlying erythema. There was no intraoral abnormality but the ipsilateral upper deep cervical lymph nodes were palpable (see Figure 1).

Correspondence: A.S.M. Jawad, M.Sc., M.R.C.P. (UK) Accepted: 22 November 1989

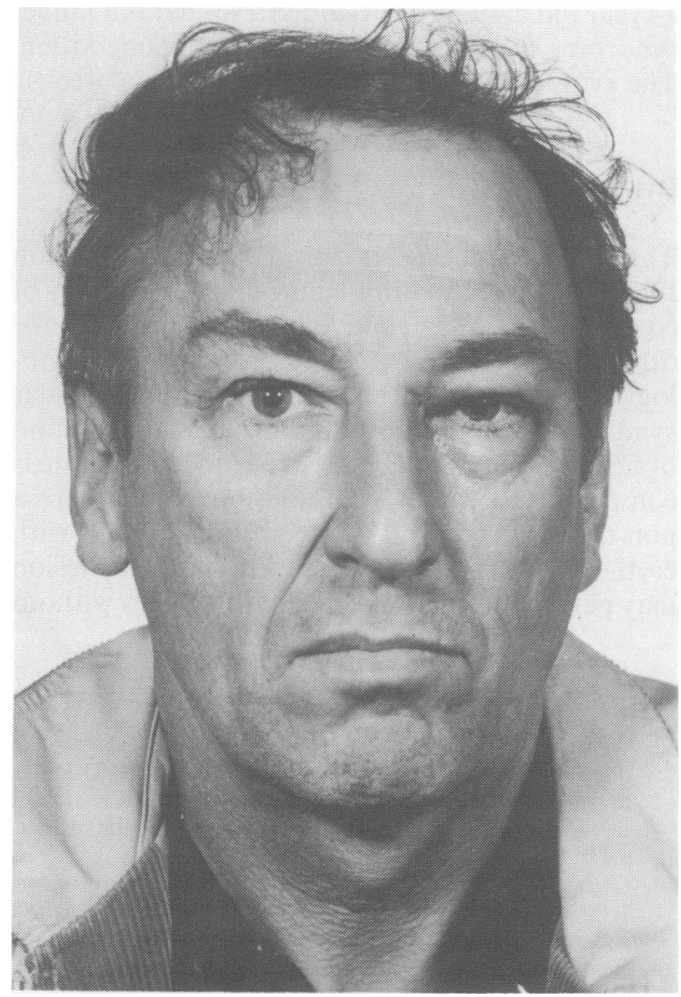

Figure 1 Shows the periorbital swelling mainly affecting the left lower eyelid and the ipsilateral preauricular swelling.

Investigations showed haemoglobin $15.9 \mathrm{~g} / \mathrm{dl}$, white cell count $13.3 \times 10^{9} / 1$ (neutrophils $72 \%$, lymphocytes $22 \%$ ), erythrocyte sedimentation rate $10 \mathrm{~mm}$ in the first hour, normal liver function tests, TPHA, autoantibodies, and the Heaf test were negative. X-ray examination of the chest and nasal 
sinuses were clear.

Trucut biopsies of the left parotid swelling and the upper deep cervical lymph nodes were performed. Histology showed both biopsies to be lymph node sections with several epithelioid granulomata with giant cells of foreign body and Langerhans types, with central necrosis containing abundant neutrophils and nuclear debris. The granulomata were surrounded by lymphocytes and plasma cells. No acid-fast bacilli, bacteria or fungi were found. These features were considered virtually diagnostic of CSD.

On subsequent questioning the man gave a clear history of being scratched on the lower eyelid by their recently acquired kitten.

No further action was taken and 3 weeks after his initial presentation the swellings of the eyelid, preauricular and cervical lymph nodes completely settled down leaving no scars in the conjunctiva.

Three weeks after this patient's presentation, his 14 year old daughter developed a similar but milder syndrome following a scratch by the same kitten. The symptoms and signs cleared within 2 weeks.

\section{Discussion}

The diagnosis of CSD in our patients was made on the basis of a compatible clinical picture, history of contact with cats, negative laboratory studies for other aetiological agents and characteristic histology of lymph node biopsy. The oculoglandular syndrome of Parinaud is an unusual manifestation of CSD seen in $2 \%$ of cases. ${ }^{5}$ The inoculation site is commonly on the palpebral conjunctiva where a non-tender, whitish/yellow granulation with erythematous margin forms. This primary lesion may persist for a few weeks and then heals without fibrosis. Ipsilateral preauricular lymph node involvement (which is sometimes accompanied by ipsilateral cervical adenopathy as in our cases) is the second component of the syndrome and may be mistaken for a parotid neoplasm. ${ }^{6}$

Henri Parinaud (1844-1905), a celebrated soldier in the Franco-German War and distinguished Paris ophthalmologist, described the oculoglandular syndrome in $1889 .{ }^{7}$ Three years earlier he had described supranuclear paralysis of upward movement of the eyes that also bears the designation of 'Parinaud's syndrome'. This causes confusion in the medical literature, hence the importance of describing the oculoglandular manifestation of CSD as 'the oculoglandular syndrome of Parinaud' rather than simply Parinaud's syndrome.

Tularemia, tuberculosis and uveoparotid fever of sarcoidosis may also present with ocular and preauricular lymph node involvement. ${ }^{8}$ However, tularemia caused by a small, pleomorphic Gramnegative bacillus ( Francisella tularensis) which can be isolated only in a culture medium containing cystine, is almost always associated with exposure to rabbits ${ }^{9}$ (though very rarely cats can acquire tularemia from hunting and feeding on infected animals such as mice or rats and can transmit the disease to humans through contaminated teeth and claws $\left.{ }^{10}\right)$. In sarcoidosis the uveal tract rather than the conjunctiva is involved.

No specific treatment is available for CSD. Spontaneous resolution of the infected lymph node is common; however, aspiration or surgical removal of the affected gland may be necessary. CSD is an important cause of solitary or regional lymphadenopathy. A retrospective history of contact with a cat, most often a kitten (which is more likely to scratch), noted in $90 \%$ of cases, is important in making the diagnosis.

\section{References}

1. Wear, D.J., Margileth, A.M., Hadfield, T.L. et al. Cat-scratch disease: a bacterial infection. Science 1983, 221: 1403-1405.

2. Margileth, A.M., Wear, D.J., Hadfield, T.L. et al. Cat-scratch disease: bacteria in skin at the primary inoculation site. JAMA 1984, 252: 928-931.

3. Gerber, M.A., Sedgwick, A.K., MacAlister, T.J., Gustafson, K.B., Ballow, M. \& Tilton, R.C. The aetiological agent of cat-scratch disease. Lancet 1985, ii: 1236-1239.

4. English, C.K., Wear, D.J., Margileth, A.M., Lissner, C.R. \& Walsh, G.P. Cat-scratch disease: isolation and culture of the bacterial agent. JAMA 1988, 259: 1347-1352.

5. Carithers, H.A. Oculoglandular disease of Parinaud: a manifestation of cat-scratch disease. Am J Dis Child 1978, 132: $1195-1200$.

6. Gallegos, N.C. \& Hobsley, M. Cat-scratch disease presenting as a lump in the parotid region. $J R$ Soc Med 1989, 82: 442.

7. Parinaud, $H$. Conjonctivite infectieuse paraissant transmise á l'homme par les animaux. Soc Ophthalmol Paris 1889, 2: 29-31.

8. Guerrant, R.L., Humphries, M.K. Jr, Butler, J.E. \& Jackson, R.S. Tickborne oculoglandular tularemia: case report and review of seasonal and vectorial associations in 106 cases. Arch Intern Med 1976, 136: 811-813.

9. Elliot, D.L., Tolle, S.W., Goldberg, L. et al. Pet associated illness. $N$ Engl J Med 1985, 313: 985-995.

10. Anonymous. Tularemia associated with domestic cats Georgia, New Mexico. $M M W R$ 1982, 31: 39-41. 